\title{
Estudo do Mercado das Mantenedoras das Cultivares de Soja no Estado do Mato Grosso
}

\author{
Market study of Maintainers of Soybean Cultivars in Mato Grosso
}

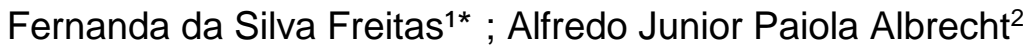 \\ "Universidade de São Paulo Escola Superior de Agricultura "Luiz de Queiroz" - Especialista em \\ Agronegócios - Estrada de Santo Amaro 365, casa 76 - CEP 05544000 - São Paulo (SP), Brasil \\ 2UFPR - Setor Palotina - Professor do Departamento de Ciências Agronômicas - Rua Pioneiro, 2153, Jardim \\ Dallas - CEP 85950-000 - Palotina (PR), Brasil
}

\section{Resumo}

O presente trabalho analisa a estrutura de mercado e a competitividade das empresas mantenedoras de cultivares de sementes de soja. Após analisar propriamente dito, a estrutura de mercado, focou-se em analisar e classificar as estratégias utilizadas bem como a competitividade das empresas no Estado do Mato Grosso, por meio de estratégias e assim identificando os fatores determinantes na competição utilizando como ferramenta de mensuração de resultados o Índice de Hirschman-Herfindahl - IHH. A observação das análises nos remetem a um nível de concentração das empresas, bem como a uma tendência oligopolista e obviamente a um aumento de competição.

Palavras-Chave: competitividade, estratégias, índice IHH

\section{Abstract}

This paper analyzes the market structure and competitiveness of the sponsoring companies of cultivars of soybean seeds. After analyzing itself, the market structure, focused on analyzing and classifying the strategies used as well as the competitiveness of companies in the state of Mato Grosso, through strategies described and thus identifying the determining factors in the competition using as a results measurement tool the Herfindahl - Hirschman index (HHI). The observation of analyzes lead us to a concentration index of companies as well as oligopolistic trend and obviously the increased competition.

Keywords: competitiveness, strategies, IHH index

\section{Introdução}

No Brasil a soja chegou via Estados Unidos, em 1882. Foi Gustavo Dutra, professor da Escola de Agronomia da Bahia que realizou os primeiros estudos de avaliação de cultivares introduzida no país. Assim como nos EUA, a soja a princípio foi estudada como uma cultura forrageira, que produziria grãos para consumo de animais, no entanto ao longo do tempo, percebeu-se que se tratava de uma cultura bastante adequada e oportuna para processamento e produção de farelo e óleo vegetal.

Em 1914 foi datado o primeiro registro de cultivo de soja no Brasil no município de Santa Rosa, RS. No entanto foi nos anos 40 que a soja se mostrou economicamente

\footnotetext{
* Autor correspondente <fernanda.freitas@yahoo.com.br> Enviado: 09 jun. 2015 Aprovado: 25 jul. 2015
} 
importante. E em 1941, obter seu primeiro registro estatístico no Anuário Agrícola do Rio Grande do Sul.

Apesar do significativo crescimento da produção ao longo de 1960, foi em 1970 que a soja se consolida como a mais importante cultura do agronegócio brasileiro (passando de 1,5 milhões de toneladas em 1970 para mais de 15 milhões de toneladas 1979). Este expressivo crescimento deu-se principalmente a três fatores, o aumento da área cultivada (de 1,3 para 8,8 milhões de hectares), incremento da produtividade $(1,14$ para $1,73 \mathrm{t} / \mathrm{ha}$ ) e a tecnologia atribuída ás pesquisas e disponibilizada aos produtores.

"Nas décadas de 1980 e 1990 repetiu-se, na região tropical do Brasil, o explosivo crescimento da produção ocorrido nas duas décadas anteriores na Região Sul. Em 1970, menos de $2 \%$ da produção nacional de soja era colhida no centro-oeste. Em 1980, esse percentual passou para 20\%, em 1990 já era superior a 40\% e em 2003 está próximo dos $60 \%$, com tendências a ocupar maior espaço a cada nova safra. Essa transformação promoveu o Estado do Mato Grosso, de produtor marginal a líder nacional de produção e de produtividade de soja, com boas perspectivas de consolidarse nessa posição" (EMBRAPA, 2005).

Na figura 1 observa-se a posição do estado do Mato Grosso, no ano de 2003, sob uma evolução desde 1960. Isso nos mostra o quanto o estado evoluiu em termos de produção de soja.

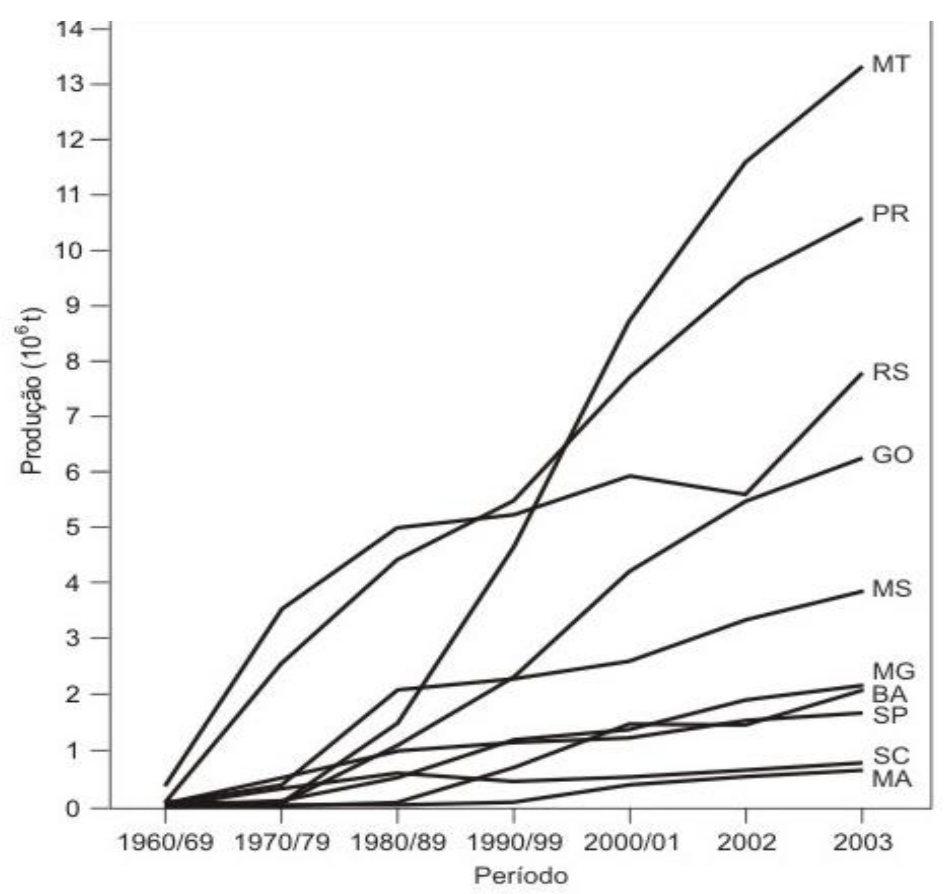

Figura 1. Evolução da produção de soja por Estado brasileiro

Fonte: EMBRAPA (2005) 
A soja foi à cultura que mais se desenvolveu ao longo dos anos (Figura 2). Fatores importantes foram primordiais para que a soja conseguisse se estabelecer como uma cultura economicamente viável. Entre os que contribuíram podemos destacar: Semelhança do ecossistema; incentivos fiscais os produtores de trigo nos anos 50, 60 e 70 e que beneficiaram a cultura de soja; mercado internacional em alta; substituição das gorduras animais (banha e manteiga) por óleos vegetais; estabelecimento de um parque industrial de processamento de soja, os incentivos fiscais do governo disponibilizados incremento da produção e estabelecimento de agroindústrias; facilidades de mecanização da cultura; surgimento de um sistema cooperativista dinâmico e eficiente, que apoiou a produção, a industrialização e a comercialização das safras.

Além destes fatores de contribuição para o estabelecimento da soja como um negócio, pode-se frisar ainda: uma rede bem articulada de pesquisa de soja e cujo envolvimento do poder público foi importante no sentido de apoia-la financeiramente; melhorias nos sistemas de integração do transporte e de comunicações.

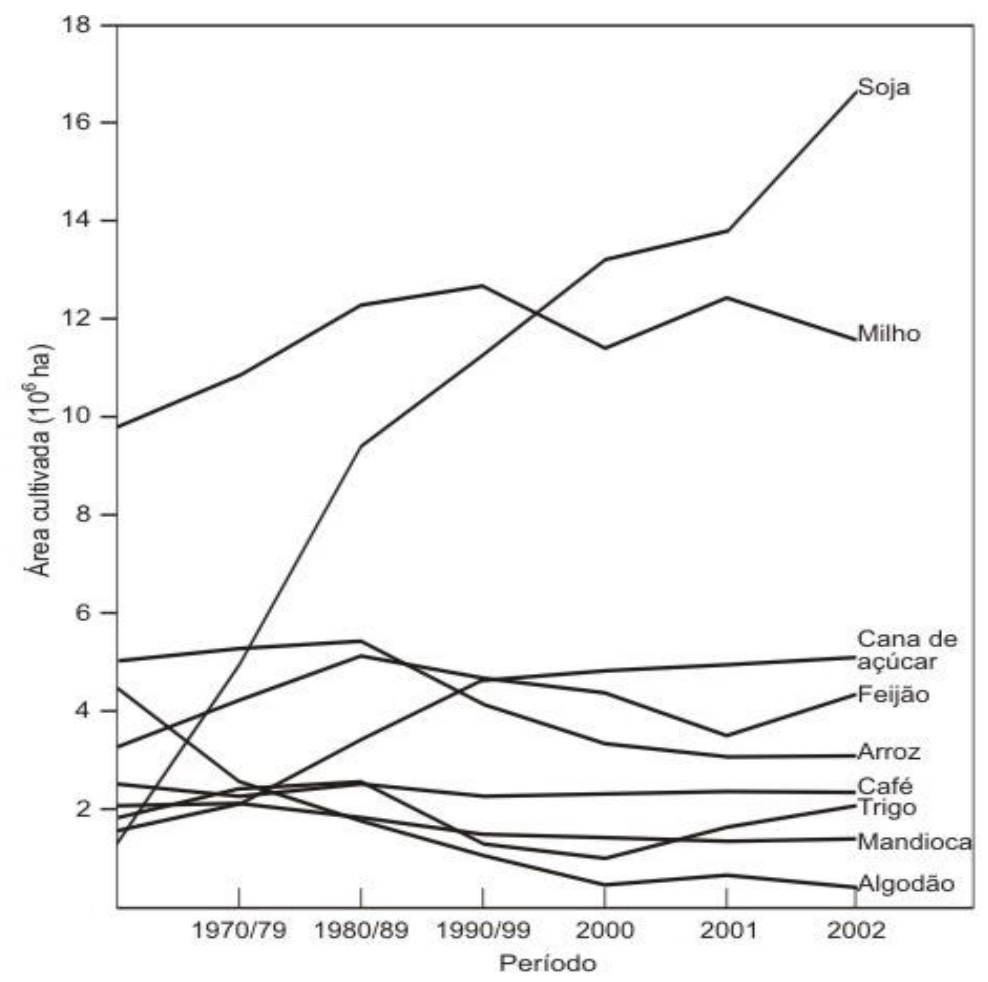

Figura 2. Área Cultivada $\times$ Cultura por período Fonte: EMBRAPA, 2005

Como já observado na figura 1, o Estado do Mato Grosso foi o que ao longo do tempo destaca-se em termos de produção. Portanto, a região Central toma uma 
importância no que se refere à produção de soja e para explicar tal crescimento e expansão podemos destacar alguns pontos de extrema relevância: a construção de Brasília o que nos remete a uma série de melhorias na região central em termos de infraestrutura. Os incentivos fiscais, para a abertura de novas áreas de produção, bem como para a aquisição de máquina e construção de silos e armazéns.

Como consequência, de tais incentivos, houve um estabelecimento de empresas agroindustriais. As terras na região central apresentavam um valor mais baixo nas décadas de 60 a 80. Topografia favorável a mecanização, o que favoreceu a utilização de máquinas e equipamentos de grande porte, proporcionando assim uma econômica de mão de obra e conseguintemente um maior rendimento econômico. Outro ponto importante é que na região existem boas condições de solo, logo facilitando as operações de maquinaria agrícola. O regime pluviométrico da região é um fator importante, principalmente para os cultivos de verão.

Portanto, um primeiro ponto que observamos é que a região central, cujo estado do Mato Grosso é parte integrante, possui uma vasta lista de característica estruturais e organizacionais que os remete ao entendimento do porque esta região possui tão forte destaque no cultivo e preparação da soja. Entende-se ainda que ao longo dos anos com o entendimento e incentivos governamentais a cultura de soja foi fortemente subsidiada e entendida como economicamente rentável.

De acordo com o Instituto Mato-grossense de Economia Agropecuária - IMEA, em 2010, o Estado do Mato Grosso bateu recorde de produção, tornando-se o primeiro estado do Brasil a superar os 20 milhões de toneladas, registrando na safra 2010/11 a maior média de produtividade, 53,3 sacas por hectare. Este resultado aponta 9,3\% de aumento na produção em relação à safra anterior (IMEA, 2010).

A partir de tais afirmações, entende-se a necessidade de análise das estruturas de mercado envolvidas nesta cultura, bem como a maneira organizacional que a mesma é distribuída. Assim, o objetivo do presente trabalho foi entender a estrutura do mercado de cultivares de soja, bem como a identificação de suas mantenedoras, no que se refere aos registros das cultivares, logo entendendo o movimento de concentração da produção de cultivares de semente no Estado do Mato Grosso.

\section{Material e Métodos}

\section{Sistema Organizacional}


Para aumentar sua produtividade e, potencializar a atuação em um mercado tão competitivo como o da soja, os agricultores do Mato Grosso têm-se utilizado de parcerias com algumas entidades federais e regionais, tais como a Embrapa, a Associação dos Produtores de Sementes de Mato Grosso - APROSMAT e a Fundação de Apoio à Pesquisa Agropecuária de Mato Grosso - FMT, além do Instituto Matogrossense de Economia Agropecuária - IMEA, Federação da Agricultura e pecuária do Estado do Mato Grosso - FAMATO, além de apoios da APROSOJA/MT, CI Soja, Centro de Inteligência de Soja de Minas Gerais e Fundação de Amparo à Pesquisa do Estado de Mato Grosso - FAPEMAT. Observa-se que estas parceiras são tão boas e que retornam bons resultados, que na safra 99/2000, Mato Grosso passou a ser o maior produtor de soja do país. Segundo Tavares (2014), nos últimos 10 anos, a produtividade no Mato Grosso chegou a alcançar 3.050 kg por hectares no ano de 2000/01.

De acordo com Cunha (2004), Mato Grosso se destaca como maior produtor de algodão e soja é também o segundo maior produtor de arroz, quarto maior produtor de girassol, quinto maior produtor de milho e o sexto maior produtor de cana-de-açúcar. Além de outras culturas como o trigo, a uva, o maracujá. Oliveira e Cassiano (2006) apontam-nos que este crescimento aparece também na arrecadação do ICMS que cresceu de $R \$ 65.044 .467,74$ em 2000 para $R \$ 93.649 .633,00$ em 2003, ou seja, aumentou cerca de $40 \%$ em três anos.

A melhor tecnologia do mundo para a produção de soja foi desenvolvida e mantem-se no Brasil, e este fato foi de forte contribuição para o status que o Brasil alcançou de ser hoje um dos maiores produtores mundiais de soja e endossa o crescimento da cultura de soja na região centro-oeste do país (Santos; Kist; Beling, 2004).

Outro fator importante é a exigência com relação à semente. Hoje os produtores de soja não dispensam a boa qualidade da soja o que se torna indispensável para uma lavoura de alto potencial. A semente, como insumo principal a semeadura, desempenha papel importante na agricultura. Serve de ponto de partida das lavouras e também representa o produto final, a produção (Zorato, 2001).

Em estudo realizado por Oliveira e Cassiano (2006), pioneiros produtores do Centro-Oeste se adaptaram a questão de que é muito mais barato comprar sementes do que tentar produzi-las ou arriscar o uso de grão próprio. A exigência de toda esta tecnologia para a produção de sementes em clima tropical motivou a criação de ampla estrutura de sementeiros e de origem, além das fundações de apoio à pesquisa nesta área (Santos; Kist; Beling, 2004). Observa-se tal fato quando se pesquisa a quantidade 
de cultivares de soja registradas o Ministério da Agricultura através do registro Nacional de Cultivares - RNC. Este desempenho do estado na produção de soja deve-se à competência dos produtores, a adaptação ás terras propicia a mecanização onde a semente de alta qualidade se mostra um elo vital de sucesso para a cadeia produtiva (Massey, 2014).

\section{Estruturas de Mercado}

A concorrência foi estimulada pela abertura da economia no país, viabilizada assim, em todos os setores. Como consequência, houve a promulgação da Lei no 8.884 , de 1994 cujo objetivo foi criar condições e garantir a defesa da livre concorrência no país (Salgado, 1997). Como consequência, há a imposição de restrições às empresas para que as mesmas não exerçam poder abusivo de suas posições no mercado em que atuam e que ainda não exerçam influencia e alianças ou fusões com empresas concorrentes. Logo, as políticas de defesa da concorrência propõem a criação de uma cultura concorrencial entre produtores e consumidores, onde as normas de competição passam a ser primordiais e necessárias para a própria existência do mercado (Considera; Araújo, 2002; Oliveira; Cassiano, 2006).

De acordo com Grawunder (1996), os mercados podem ser classificados em duas grandes categorias: concorrência perfeita e concorrência imperfeita. A concorrência perfeita é caracterizada por uma estrutura em que um produto homogêneo tem elevado número de compradores e vendedores. Assim, a atuação isolada de um comprador ou vendedor não exerce influência neste mercado. Já a concorrência imperfeita tem por característica se ao contrário da anterior. São mercados de concorrência imperfeita aqueles em que ou existe diferenciação do produto ou o número de compradores ou vendedores não é grande.

Para um melhor entendimento da estrutura de mercado é adequado o melhor entendimento de seu grau de concentração. De acordo com Parré e Silva (2002) a concentração industrial está intimamente ligada à competição. Em um mercado onde é perceptível a existência de um número pequeno de grandes e consideráveis empresas, a competição entre elas pode de algum modo desfavorecer o consumidor final, ou ainda um pequeno número de empresas, o que pode favorecer a tomada de decisão em relação ao preço, que é fundamental no processo de decisão de compra.

Uma empresa posiciona-se dentro de seu setor vislumbrando sua rentabilidade, ou seja, ela pode optar em ter uma rentabilidade acima das demais, abaixo, ou simplesmente, estar na média, isso acontece independente da estrutura organizacional 
interna ser favorável ou não. A empresa obtém como resultado, vantagem competitiva, quando consegue, em um longo prazo, desempenho acima da média, ou simplesmente por ofertar algo tão diferenciado que potencializa os seus ganhos e resultados.

De acordo com Porter (1997), há apenas duas maneiras de obtenção de vantagens competitivas: custos baixos e diferenciação. A combinação desses dois tipos básicos de vantagem competitiva e o objetivo de atividades leva a três estratégias genéricas, que são: a) Liderança no custo; b) Diferenciação; c) Enfoque. Pode-se ainda considerar um quarto tipo, que seria um "meio-termo".

Por um lado, as estratégias abrangentes de liderança no custo e diferenciação buscam um apanhado maior de segmentos para a obtenção da vantagem competitiva, por outro lado a estratégia do enfoque propõe a atuação em um segmento menor e objetiva-se na obtenção de uma vantagem competitiva através de custo e diferenciação.

Para entender se a empresa vai crescer mais do que as suas concorrentes, precisa atentar em como a combinação destes fatores influenciaria nas decisões a serem tomadas, ou seja, a vantagem competitiva é resultado do conjunto de ações estratégicas determinadas pelos heads, ou, os que gerenciam e dirigem as empresas, que vislumbram um desempenho maior ou superior nos fatores determinantes e críticos de sucesso, na perspectiva do cliente e focando a atuação dos concorrentes. São estas as ações que se concentradas, é que definem a opção de compra, ou melhor, a oferta de opções de compra para os clientes e que são entendidos como fatores de críticos de sucesso.

\section{Liderança no Custo}

Para Porter (1986), a liderança no custo foi a primeira estratégia, que se tornou latente nos anos 70, através da popularização da curva de experiência, onde os custos se minimizam em decorrência do tempo, ou seja, quanto mais o tempo passa, mais se tem ideia do quanto se gasta o que torna a organização mais competitiva em decorrência dos controles categóricos dos custos e despesas gerais, além de não permitir a formação de contas marginais dos clientes. As fontes desse baixo custo variam e dependem do tamanho e dimensão das empresas.

Segundo Oliveira e Cassiano (2006) a curva de experiência, às vezes, é uma frágil barreira à entrada no setor agrícola - mais especificamente de produção de soja. O novo concorrente poderá ter mais eficiência que os produtores mais experientes à medida que disponha de equipamentos mais modernos que os deles. Nesse caso, os produtores mais experientes perdem em produtividade à medida que o concorrente 
alcança economia de escala através de instalações e equipamentos mais eficientes e automatizados. Outro ponto a se destacar que além da tecnologia maquinaria, existe a perspectiva da semente. Apenas, relembrando, um experiente produtor é aquele que busca tecnologia, bem como, a semente de melhor qualidade para potencializar sua produção.

A ideia de minimizar custos ou diferenciar-se é bastante presente no que se refere a competição das empresas no fornecimento de sementes de soja para os produtores de Mato Grosso, no entanto, este assunto será abordado mais adiante.

Segundo Porter (1990) a proximidade na diferenciação significa que o desconto de preço necessário para obter uma parcela de mercado aceitável não compensa a vantagem de um líder no custo e, portanto, este líder no custo obtém retornos acima da média.

\section{Diferenciação}

De acordo com Porter (1986), a diferenciação consiste na habilidade da organização em diferenciar-se da concorrência através de um ou mais atributos englobando o preço que ao ver dos consumidores, é singular e valioso. Da perspectiva de consumo, o consumidor, entende e dá o real valor as empresas que conseguem ter um produto e/ou serviço te tenha a capacidade de satisfazer e se adequar ás suas necessidades. A ideia de estar presente na vida dos consumidores com um posicionamento forte e latente nos remete a empresas que possuem diferenciais significativos e se distanciam de seus concorrentes, ou seja, elas terão superior vantagem competitiva.

Tweed (1998) afirma que "A diferenciação pode estar na percepção da qualidade ou do valor superior, ou por conseguir capitalizar os hábitos emocionais de compra do consumidor". Ainda na perspectiva de Porter (1986), a diferenciação proporciona uma estratégia de isolamento frente às concorrentes graças à fidelidade e lealdade do consumidor em relação a marca e é claro, em relação ao preço. Há a possibilidade de uma empresa criar barreiras de entradas para seus concorrentes, estimulando a fidelidade e também a supremacia de oferta dos produtos ofertados por ela, e como consequência, um resultado satisfatório em seus resultados. "Deve ser ressaltado que a estratégia de diferenciação não permite à empresa ignorar os custos, mas eles não são o alvo primário ou principal" (Porter, 1986).

Alguns riscos podem ser provocados pela diferenciação elencados por Porter (1986): Concorrentes com baixo custo ganham a lealdade dos clientes e pode deixar de 
lado o diferencial, o que conseguintemente gera uma redução importante de custo; Imitação reduz a diferenciação percebida, uma ocorrência comum quando a indústria amadurece.

\section{Enfoque}

A estratégia genérica do enfoque objetiva a restringir um leque de opções de atuação como um ambiente competitivo dentro das empresas e que busca atender seus objetivos alvo, ou setores foco desenvolvendo assim, a vantagem competitiva. Consequentemente, a empresa atinge a diferenciação por satisfazer melhor as necessidades de seu alvo particular, ou através de custos mais baixos na obtenção deste alvo, ou ambos (Porter, 1986).

Porter (1986) sinaliza que essa estratégia se divide em duas vertentes: no "enfoque no custo" e no "enfoque na diferenciação": 1ํ Enfoque no custo - vantagem de custo no segmento-alvo; $2^{\circ}$ Enfoque na diferenciação - vantagem na diferenciação em seu segmento-alvo. A estratégia de enfoque objetiva suprir a insatisfação dos clientes atendidos pelos concorrentes com alvos amplos. O ponto principal do enfoque é a diferença de um alvo estreito em relação ao todo, o que é explorado intensamente.

Segundo Porter (1986), alguns riscos incorrem nesta estratégia, são eles: O diferencial de custos entre os concorrentes que atuam no mercado, bem como as empresas que adotaram enfoques particulares ampliando o poder de eliminar as vantagens de custos de atender um alvo estreito ou ainda anular a diferenciação alcançada pelo enfoque. Os concorrentes podem encontram sub-mercados dentro do alvo estratégico e tirando o objetivo da empresa com estratégia de enfoque.

\section{O meio-termo}

De acordo com Porter (1986), “[...] a premissa básica que norteia uma estratégia genérica é de que estas são métodos alternativos viáveis para lidar com as forças competitivas e visam a criação e a sustentação de uma vantagem competitiva". Muitas organizações assumem uma postura indefinida em relação às estratégias competitivas genéricas (liderança no custo, diferenciação e enfoque), adotando uma postura estratégica que se mantem no "meio-termo", o que demonstra uma estratégia pobre e de poucas opções para a empresa. Normalmente a empresa que opta pela estratégia "maio termo" tem como resultante uma baixa rentabilidade, pois fica inconsistente e pouco ousada nas redefinições e atuações de preços, perdendo vendas de grandes volumes e assim ficando em situação delicada no mercado (Porter, 1986). 
Porter (1986) propõe que uma empresa deve adotar alguma medida: Ou ela adota para alcançar a liderança - ou mesmo a paridade - de custo, o que normalmente resulta em investimentos agressivos para modernizar e, talvez, a necessidade investimentos em compra de parte do mercado em que ela atua, ou ainda deve orientarse para um alvo determinado (enfoque) ou atingir alguma supremacia (diferenciação).

Aparentemente a empresa que se posiciona "meio termo" não tem uma cultura clara de atuação e é percebido que a execução bem-sucedida de cada estratégia na empresa requer diferentes atributos e estilos de administrar, principalmente disposição e ousadia organizacional. No entanto, são raras as empresas que se preparam e atuam nas três vertentes estratégicas. Observa-se que por todas estas inconsistências, as empresas que se posicionam como "meio termos" estão fadados ao fracasso (Porter, 1986).

\section{Materiais e Métodos}

Para analisar a concentração de mercado de segmento de produção de sementes de soja, utilizaram-se índices que avaliam o grau de concorrência nos mercados. Por considerar que a concentração industrial é um dos principais determinantes da competição, a mensuração dessa variável fornecerá elementos para a avaliação do nível concorrencial nos mercados. Para Massey (2014), a mensuração de indicadores para concentração de mercado está diretamente relacionada com a capacidade produtiva, o valor e a quantidade de vendas.

O Índice Herfindahl-Hirschman - IHH avalia o grau de concentração do mercado relevante sendo calculado por meio da soma dos quadrados dos Market share individuais das empresas participantes no mercado relevante, tendo a vantagem de refletir a distribuição do tamanho das empresas, em relação ao peso conferido às empresas com elevado Market share é maior do que aquele relativo às empresas com baixo Market share. Seu valor oscila entre 0,18 (base decimal podendo ser utilizado na base \%) para o caso do monopólio/ou concentração e menos de 0,1 base decimal podendo ser utilizado na base \%), para concorrência não concentrada.

Assim, percebe-se que quanto mais concentrado o mercado, maior será o $\mathrm{IHH}$, definido pela equação 1

$$
\mathrm{IHH}=\Sigma \mathrm{S}_{1}^{2}+\mathrm{S}_{2}^{2}+\ldots \mathrm{S}^{2}
$$


Onde, IHH: Índice Hirschaman-Herfindahl; $\mathrm{S}_{1}$ : Participação porcentual no mercado da empresa 1; $S_{2}$ : Participação porcentual no mercado da empresa 2; $S_{n}$ : Participação porcentual no mercado da empresa $n$.

No que se refere a analise $\mathrm{IHH}$ que utilizaremos no estudo, apresentaremos a mesma, com uma metodologia muito utilizada por estudiosos e especialistas, conforme Tabela 1 (USDOJ, 1992).

Tabela 1. Relação de Concentração de Mercado

\begin{tabular}{ll}
\hline \multicolumn{2}{c}{ Concentração de Mercado } \\
\hline Não concentrado & $\mathrm{IHH}<0,1$ \\
Moderada & $0,1<\mathrm{HH}<0,18$ \\
Alta & $\mathrm{IHH}>0,18$
\end{tabular}

Fonte: USDOJ, $199 \overline{2}$

O presente trabalho tem por característica um estudo da concentração das empresas mantenedoras e/ou requerentes de cultivares de soja no estado do Mato Grosso, tomando por base de análise os dados disponibilizados pelo Ministério da Agricultura em seu sítio oficial de internet, ao qual nos apresenta o Registro Nacional de Cultivares.

Analisou-se os registros no RNC da cultura de soja (Glycine max (L.) Merr.), dados estes, registrados até novembro de 2014, onde as variáveis utilizadas foram: Empresa Mantenedora (requerente) do registro da semente de soja, a quantidade de registros realizadas até o momento, bem como o estado ao qual esta empresa origina seus registros - vale salientar que a base de dados nos indica para alguns casos a região de adaptação da semente, no entanto como para a maioria dos casos esta opção não é visível, o estudo pauta-se no estado de origem da Mantenedora do registro.

Calculou-se o Market share em relação a quantidade de registros totais e identificou-se que 20 empresas são responsáveis por $62 \%$ dos registros, sejam eles de sementes de soja transgênica ou não. Após esta identificação, foi explorado a Market share por estado, entendendo que o estado do Mato Grosso, até novembro de 2014, apresenta 125 registros, ocupando assim a 5a colocação no ranking.

Estreitou-se mais a análise, e das empresas que registraram efetivamente 0 cultivo de sementes de soja no Mato Grosso. Foram identificadas cinco empresas, sendo que a que mais contribui com o registro de sementes de soja é a Fundação De Apoio a Pesquisa Agropecuária De Mato Grosso - Fundação MT, apresentando Market share de $45 \%$. 
As empresas analisadas neste primeiro momento foram responsáveis por $62 \%$ dos registros, ou seja, as 20 principais empresas solicitaram o registro de 1.472 cultivares de soja, sendo que a oitava empresa no ranking com 57 registros foi a principal empresa atuante nos registros do Mato Grosso.

A escolha do Estado do Mato Grosso e da métrica registro da semente de soja deu-se por conta do estado ser o maior produtor de soja do Brasil e ter uma responsabilidade bastante expressiva neste mercado que se torna cada vez mais abrangente.

$\mathrm{Na}$ Tabela 2 observa-se o ranking de Market share em relação ao número de registro das principais mantenedoras de Cultivares de soja.

Tabela 2. Market Share das Mantenedoras de Cultivares de Soja (Glycine max (L.) Merr.) no Registro Nacional de Cultivares - RNC, novembro de 2014

\begin{tabular}{lccc}
\hline \multirow{2}{*}{ Mantenedor (Requerente) } & \multirow{2}{*}{ № de Registros } & \multicolumn{2}{c}{ Participação (\%) } \\
\cline { 3 - 4 } & 248 & 0,167 & 0,167 \\
\hline EMBRAPA & 149 & 0,100 & 0,267 \\
Monsoy & 123 & 0,083 & 0,349 \\
Gdm Genética |Gdm Licenciamento & 109 & 0,073 & 0,423 \\
Coocentral & 97 & 0,065 & 0,488 \\
Nidera Sementes & 81 & 0,054 & 0,542 \\
Syngenta Seeds Ltda & 64 & 0,043 & 0,585 \\
Bayer S.A. & 57 & 0,038 & 0,624 \\
Fundação Mato Grosso & 50 & 0,034 & 0,657 \\
Tmg Tropical Melhoramento e Genética & 45 & 0,030 & 0,688 \\
Dupont Do Brasil S/A & 44 & 0,030 & 0,717 \\
Fts Sementes S.A & 44 & 0,030 & 0,747 \\
Empresa Brasileira de P. Agropecuária & 44 & 0,030 & 0,776 \\
Unisoja S/A & 35 & 0,024 & 0,800 \\
Cooperativa Central Gaúcha Ltda & 31 & 0,021 & 0,821 \\
Universidade Federal De Viçosa-Ufv & 24 & 0,016 & 0,837 \\
Instituto Agronômico - lac & 17 & 0,011 & 0,848 \\
Agro Norte Pesquisa E Sementes Ltda & 20 & 0,013 & 0,862 \\
Empresa de P. Agropecuária de MG & 15 & 0,010 & 0,872 \\
Br Genética Ltda & 13 & 0,009 & 0,880 \\
Empresa Ass. T. e. Rural Est. Goiás & 178 & 0,120 & 1,000 \\
Outros & $\mathbf{1 4 8 8 1}$ & $\mathbf{1 0 0 , 0 0}$ & \\
Total & & & \\
\hline Fotal & & &
\end{tabular}

Fonte: Elaborado pela autora, 2014

${ }^{1} \mathrm{O}$ número de empresas com registro no RNC (1488) é maior que o número de cultivares registradas (1300) pelo fato de existirem cultivares registradas e desenvolvidas em associação, ou seja por mais de uma organização, o que gera duplicidade no total de empresas listadas como mantenedoras de registros. Adaptado dos dados do Ministério da Agricultura Pecuária e Abastecimento (BRASIL, 2014). 
$\mathrm{Na}$ Tabela 3 torna-se mais evidente a importância do estado no desenvolvimento e registro das sementes de soja. Vale salientar ainda que o estado possui parcerias estratégicas com outras empresas para o melhoramento e desenvolvimento genético de sementes de soja, tais como com a empresa Unisoja do Estado do Mato Groso e a emprese TMG Tropical Melhoramento e Genética do Paraná.

Tabela 3. Market Share por estado de mantenedoras de Cultivares de Soja (Glycine max (L.) Merr.) no Registro Nacional de Cultivares -RNC, novembro de 2014

\begin{tabular}{|c|c|c|c|}
\hline \multirow{2}{*}{$\begin{array}{l}\text { Mantenedor (Requerente) } \\
\text { Estado de Origem }\end{array}$} & \multirow{2}{*}{ № de Registros } & \multicolumn{2}{|c|}{ Participação (\%) } \\
\hline & & Share & Acumulado \\
\hline$\overline{P R}$ & 358 & 0,241 & 0,241 \\
\hline SP & 318 & 0,214 & 0,454 \\
\hline DF & 300 & 0,202 & 0,656 \\
\hline$M G$ & 193 & 0,130 & 0,786 \\
\hline MT & 125 & 0,084 & 0,870 \\
\hline RS & 110 & 0,074 & 0,944 \\
\hline GO & 55 & 0,037 & 0,981 \\
\hline NA & 20 & 0,013 & 0,994 \\
\hline MA & 3 & 0,002 & 0,996 \\
\hline SC & 2 & 0,001 & 0,997 \\
\hline Total & 1488 & 1,000 & \\
\hline
\end{tabular}

Fonte: Elaborado pela Autora, 2014

\section{Resultados e Discussão}

A indústria de sementes é caracterizada por investir fortemente em pesquisa e desenvolvimento, melhoramento genético de plantas, de novas variedades de plantas, algumas com características bem especificas, por exemplo para a adaptação á diferentes regiões brasileiras. Um marco interessante para o mercado foram normas jurídicas estabelecidas que destaca a Lei $n .-10.711 / 2003$, que cria o Sistema Nacional de Sementes e Mudas - SNSM, no âmbito do Ministério da Agricultura, Pecuária e Abastecimento - MAPA, para "garantir a identidade e a qualidade do material de multiplicação e de reprodução vegetal produzido, comercializado e utilizado em todo o território nacional" (Art. 1. ${ }^{\circ}$ da Lei n. ${ }^{\circ}$ 10.711/2003); e a Portaria n. 527/1997, que instituiu o Registro Nacional de Sementes e Mudas - Renascem, e o Registro Nacional de Cultivares - RNC, hoje regido pela Lei $n .010 .711 / 2003$ e regulamentado pelo Decreto n. ${ }^{\circ} 5.153 / 2004$, cuja finalidade é habilitar cultivares para a produção e a comercialização de sementes e mudas. 
A partir dos registros consolidados do RNC foi possível analisar a estrutura do mercado e o nível de concorrência na oferta de sementes de soja para o mercado do Mato Grosso. Os registros do RNC extraídos até novembro de 2014 nos remetem a existência de 1333 cultivares de soja registradas, das quais 65\% são mantidas por Empresa Brasileira De Pesquisa Agropecuária - Embrapa, Monsoy Ltda, Cooperativa Central De Pesquisa Agrícola - Coocentral, Nidera Sementes Ltda, Syngenta Seeds Ltda, Gdm Genética Do Brasil Ltda, Gdm Licenciamento Do Brasil Ltda, Bayer S.A., Fundação De Apoio à Pesquisa Agropecuária de Mato Grosso - Fundação MT, TMG Tropical Melhoramento e Genética Ltda, Dupont Do Brasil S/A - Divisão Pioneer Sementes - FTS Sementes S.A., Unisoja S/A, Cooperativa Central Gaúcha Ltda - CCGL Tecnologia, Universidade Federal De Viçosa - UFV, Instituto Agronômico - IAC, Agro Norte Pesquisa e Sementes Ltda, Empresa de Pesquisa Agropecuária de Minas Gerais.

Após as análises de $\mathrm{IHH}$, das empresas produtoras de semente de soja, do Estado do Mato Grosso, verificou-se que o grau de concentração é alto, ou seja, no Estado existe um forte poder de mercado por qualquer empresa que atue no mesmo.

O exercício do $\mathrm{IHH}$ foi uma importante ajuda e reforça a ideia de que as empresas possuem uma determinada característica competitiva, e nos remete a uma concentração alta, ou seja, poucos players originários no Estado do Mato Grosso são responsáveis pelo fornecimento de cultivares de soja. Sendo que estes cinco players junto apresentam índice de 0,35 onde o índice balizador de alta concentração é de 0,18.

$\mathrm{Na}$ análise da tabela 4 pode-se aferir que a estrutura do mercado de registros de sementes de soja no Estado do Mato Grosso remete a uma concorrência imperfeita, pois existe diferenciação nos produtos (pode-se destacar o fato da semente ser transgênica ou não) A concorrência no mercado de sementes de soja no estado é oligopolista e fortemente acirrada. Pindyck e Rubinfeld (2002, p. 427) afirmaram que, em mercados oligopolistas, os produtos podem ou não ser diferenciados.

O importante é que apenas algumas empresas são responsáveis pela maior parte ou por toda a produção. Em alguns desses mercados, algumas ou todas as empresas obtêm lucros substanciais em longo prazo, já que barreiras à entrada tornam difícil ou impossível que novas empresas entrem no mercado. 
Tabela 4. Calculo do IHH das Empresas Mantenedoras (requerentes) de cultivares de soja no Estado do Mato Grosso

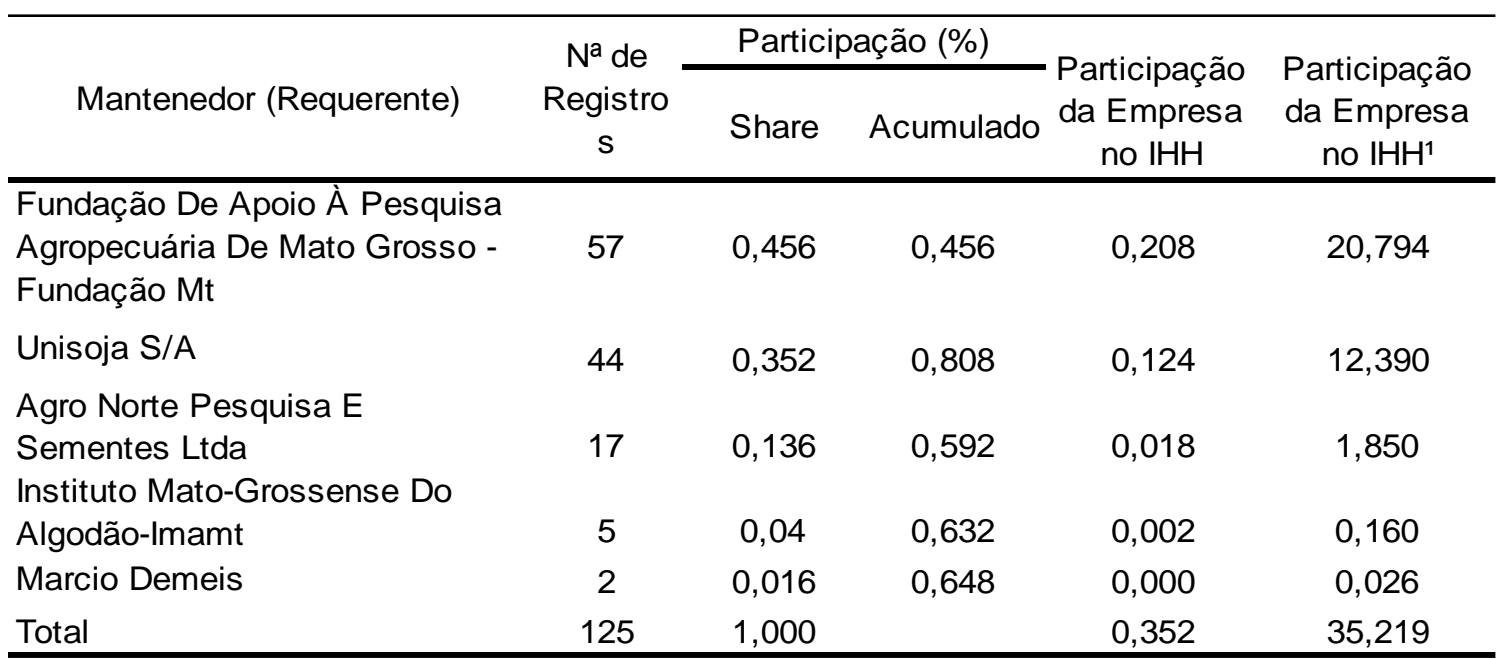

Fonte: Elaborado pela autora, 2014

${ }^{1} \mathrm{HHH}$, na base 100: de acordo com as considerações apresentadas por Klemperer (1996) e Mendes (1998) citados em Noce et al (2005), os quais adotam a participação percentual expressa como 100\% $=100$

A alta concentração de mercado no estado, destacada pelo Market share, foi atestada pelo $\mathrm{IHH}$ (Tabela4). $\mathrm{O} \mathrm{IHH}$ do segmento de sementes evoluiu no estado a uma taxa considerável. De 2011 para 2014 obteve um crescimento de 66\% na quantidade de registro de sementes de soja, demonstrando que a trajetória de concentração dessas empresas, além de extremamente elevada, continua aumentando.

Em um cenário de domínio absoluto de patentes sobre as sementes das cultivares mais produtivas faz com que os produtores se tornem reféns desta estratégia e já que o preço é dado e calibrado pelas empresas, concentra nas empresas a detenção de informações um controle maior do mercado e os produtores trabalham sem opção a não ser aumentar escala de produção para vislumbrarem maiores ganhos. Como consequência desta pressão os produtores, na busca de continuarem na atividade, tendem a pressionar por subsídios pagos pela sociedade.

Como resultado deste tipo de integração produtiva tem-se uma condução as perdas de competitividade empresarial e global neste (quando observa a perspectiva do produtor de soja) segmento tão importante da economia. A consequência, é que neste cenário a contribuição da produção para o desenvolvimento do estado e da região fica bastante comprometido e ao invés dos produtores alavancaram a renda, observam a mesma ser reduzida, resultando em baixos investimentos para a mitigação de possíveis impactos ambientais e ao intensivo uso de mão de obra.

Em contrapartida, o governo deve avançar com as políticas de regulação do setor, com investimentos em ciência e tecnologia, garantindo assim a continuidade de 
recursos para as Universidades e Instituições públicas, para alavancar a pesquisa em genética e biotecnologia de forma paralela e não integrada com a iniciativa privada.

Por fim, entende-se que o segmento de sementes seja no Estado do Mato Grosso, seja no Brasil, ou até mesmo no mundo, tende a investir fortemente no conhecimento cientifico, tecnológico e da inovação, sendo óbvia a concentração de informação de todos os níveis de mercado da cadeia de soja, utilizando-se de barreiras para a entrada de concorrentes, mediante a criação de propriedade intelectual, bem como a estratégia de manter os investimentos em pesquisa, desenvolvimento e inovação, pode limitar de certo modo a capitalização dos produtores em função da trajetória de concentração ser evidente e crescente.

\section{Conclusões}

A cultura de soja impulsiona a economia do Estado do Mato Grosso, sendo que a produção foi viabilizada pelo desenvolvimento de novas cultivares de sementes de soja. Muito por conta de parcerias entre empresas e o estreitamento entre Governo e Instituições de ensino e pesquisa.

Utilizando o métoddo de nivel de concentração conhecido por $\mathrm{IHH}$, identifica-se um alto nivel de concentração no registro de cultivares de semente de soja. No Estado do Mato Grosso, existem hoje cinco empresas (originárias da região) responsáveis pela submissão de registros junto ao Ministério da Agricultura. Identifica-se ainda uma estrutura de mercado com forte tendência a concorrência imperfeita, tendendo assim á um oligopólio.

Como trata-se de um mercado muito competitivo, as empresas produtoras de sementes de soja, utilizam-se de subterfugios diferentes para a conquista de suas fatias de mercado. Dentre as estratégias utilizadas como vantagem competitiva, por exemplo a eficiência produtiva, a prestação de serviços agrícolas de alta qualidade, além de uma enorme difusão tecnologica. Portanto, hoje o que há de melhor em tecnologia é utilizado neste estado como fator estratégico.

Identifica-se influências competitivas importantes nas empresas produtoras de sementes de soja, no Estado do Mato Grosso, são elas: a rivalidade da concorrência, onde observa-se uma concentração entre duas empresas, que detem $80 \%$ do mercado, sendo que entre estas duas, há um equilibrio em termos de quantidade de registros, no entanto este tipo de "equilibrio" pode ocasionar uma "disputa por preços" entre estes concorrentes. Um segundo aspecto é o poder de negociação, ou seja os clientes destas empresas compram grandes quantidades, e detem informações sobre preços e 
tecnologias, logo exprimem fortes pressões para redução de preços, no entanto como vimos, muitas vezes ficam em uma situação não tão confortavel, uma vez que com custos tão altos não conseguem potencializar seus ganhos.

\section{Referências}

Associação dos Produtores de Soja e Milho do Estado de Mato Grosso [APROSOJA]. 2014. Indicadores e Cotações. Disponível em <http://www.aprosoja.com.br/> acesso em 26 out. 2014.

Santos, C.; Kist, B.B.; Beling, R.R. 2004. Anuário brasileiro de soja. Santa Cruz do Sul: Gazeta Santa Cruz. 144 p.

Instituto Mato-grossense de Economia Agropecuária [IMEA]. 2014. Estatísticas e Notícias. Disponível em: < http://www.imea.com.br/ > . Acesso em: 26 out. 2014.

Empresa Brasileira de Pesquisa Agropecuária [EMBRAPA]. 2014. Notícias. Disponível em: <http://www.imea.com.br/noticias.php?id=722\#> Acesso em: 26 out. 2014.

Empresa Brasileira de Pesquisa Agropecuária [EMBRAPA]. 2014. Notícias. Disponível em <http://www.conab.gov.br/site/conteudos.php?a=1252\&t=2\&Pagina_objcmsconteudos =3\#A_objcmsconteudos $>$ acesso em 26 out. 2014 .

Empresa Brasileira de Pesquisa Agropecuária [EMBRAPA]. 2014. Produção de Soja no Brasil. Disponível em <http://www.cnpso.embrapa.br/producaosoja/SojanoBrasil.htm> acesso em 26 out.2014.

Empresa Brasileira de Pesquisa Agropecuária [EMBRAPA]. 2014. Produção de Soja no Brasil item: Tabelas. Disponível em <http://www.cnpso.embrapa.br/producaosoja/tab/fig_0_2.htm> acesso em 26 out. 2014.

Ministério da Agricultura Pecuária e Abastecimento [MAPA] 2014. Registro Nacional de Cultivares. Estatísticas on-line. 2011. Disponível em:

<http://extranet.agricultura.gov.br/php/snpc/cultivarweb/cultivares_registradas.php>. Acesso em: 05 nov. 2014.

Centro de Inteligência de Soja [CISOJA]. 2014. Notícias e Dados e Estatísticas.

Disponível em <http://www.cisoja.com.br/> acesso em 26 out. 2014. 
Considera, C.M.; Araújo, M.T. 2002. Competition Advocacy in Brazil - Recent Development. Ministério da Fazenda/SEAE, p. 1-12.

Cunha, R.B.C. 2004. Maio verde mostra que Mato Grosso é destaque. Disponível em: http://www.primeirahora.com.br/artigos/view.htm Acesso em: 13 ago. 2004.

Empresa Brasileira de Pesquisa Agropecuária [EMBRAPA]. 2005. Tecnologias de produção de soja - Paraná: 2005. Londrina: Embrapa Soja. (Sistemas de Produção, n. $5)$.

Empresa Brasileira de Pesquisa Agropecuária [EMBRAPA]. 2011. Tecnologias de produção de soja - região central do Brasil 2012 e 2013. Londrina: Embrapa Soja. (Sistemas de Produção, n. 15).

Grawunder, A.F. 1996. Mercado de Produtos. In: Nali de Jesus de Souza (coordenador). Introdução à Economia. São Paulo: Atlas. p. 113-136.

Massey Ferguson. 2014. Sementes com vigor produzidas sem dano mecânico. Disponível em: http://www.massey.com.br/portuguÊs/campo.html Acesso em: 13 nov. 2014.

Noce, R.; Silva, M.L. da; Carvalho, R.M.M.A. 2005. Concentration of the exports in the international market of sawn wood. Rev. Árvore. 29 (3):431-437.

Oliveira, L.H. de; Mesquita, C.R. 2006. Estrutura de mercado e competitividade das empresas produtoras de sementes de soja da região Sul de Mato Grosso. XLIV Congresso da SOBER - Sociedade Brasileira de Economia e Sociologia Rural. "Questões Agrárias, Educação no Campo e Desenvolvimento". Anais... Universidade de Fortaleza - UNIFOR - Fortaleza, 23 a 27/07/2006.

Parré, J.L.; Silva, A.N.J. da. 2002. Comparação das informações apresentadas por revistas nacionais acerca do setor de telecomunicações no Brasil. Revista Teoria e Evidência Econômica, Passo Fundo. 10(8): 109-132.

Pindyck, R.S.; Rubinfeld, D.L. 2002. Microeconomia. 5. ed. Trad. de Eleutério Prado. São Paulo: Prentice Hall.

Porter, M.E. 1986. Estratégia Competitiva: técnicas para análise de indústrias e da concorrência. Trad. de Elizabeth Maria de Pinho Braga. 7. ed. Rio de Janeiro:

Campus. 
ano 1, n. 1, p. 88.

1997. Os caminhos da lucratividade. HSM Management, Barueri, 1990. Vantagem Competitiva: criando e sustentando um desempenho superior. 9 ed. Rio de Janeiro: Campus.

Salgado, L.H. 1997. A Economia Política da Ação Antitruste. Ed. Singular, São Paulo.

Tavares, C.E.C. 2014. Fatores críticos à competitividade da soja no Paraná e no Mato Grosso. Disponível em: http://www.conab.gov.br/dowload/cas/especiais/. Acesso em: 13 nov. 2014

Tweed, S.C. 1998. Foco estratégico: a vantagem competitiva. São Paulo: Ed. Gente

United States Department of Justice [USDOJ]. 1992. The Hirschman - Herfindahl Index.

Zorato, M. de F. 2001. SQS - Garantia de Qualidade. SEED News: a revista internacional de sementes 1:12-13. 